\title{
CONDIÇÃO BUCAL E HÁBITOS DE PRATICANTES DE ATIVIDADES FÍSICAS AMADORAS.
}

\author{
Victoria Sorente de Oliveira*, Dagmar de Paula Queluz.
}

\section{Resumo}

O objetivo deste estudo foi avaliar clinicamente a condição bucal e investigar os hábitos de praticantes de atividades físicas amadoras de maneira a auxiliar no maior reconhecimento do cirurgião-dentista dentro do ambiente esportivo visando a prevenção de possíveis lesões. A coleta de dados foi realizada pela aplicação de questionários sobre os hábitos durante a prática esportiva e exame clínico intraoral de adolescentes de 15-18 anos que praticam atividade física regularmente em escolinhas de futebol da cidade de Piracicaba - SP. 16 adolescentes participaram do estudo. Em relação ao uso de protetor bucal durante a prática de atividades físicas, mais de $81 \%$ dos entrevistados relataram achar importante o uso, porém apenas 19\% realmente o fazem. A maioria dos adolescentes não estão familiarizados com a presença no dentista na equipe multidisciplinar envolvida com os esportistas e não realizam tratamento odontológico visando uma melhora nos resultados físicos. O estudo permiti concluir que a atuação do cirurgião-dentista no ambiente esportivo ainda é pouco conhecida. Além disso, entre os atletas amadores, poucos relatam fazer acompanhamento odontológico, o que demonstra desconhecimento do impacto da saúde bucal em relação a saúde sistêmica.

Palavras-chave: Exercício, Saúde bucal, Odontologia.

\section{Introdução}

Odontologia do Esporte é a área de atuação do cirurgião-dentista que inclui segmentos teóricos e práticas da Odontologia, com o objetivo de investigar, prevenir, tratar, reabilitar e compreender a influência das doenças da cavidade bucal no desempenho dos atletas, com a finalidade de melhorar o rendimento esportivo e prevenir lesões, considerando as particularidades fisiológicas dos atletas, a modalidade que praticam e as regras do esporte.

A atuação do cirurgião-dentista dentro do ambiente esportivo como parte de uma equipe multidisciplinar é ampla, incluindo não só o tratamento de trauma e uso de protetores bucais, mas também a prevenção e tratamento de doenças bucais que podem atrapalhar no rendimento do atleta.

O objetivo deste estudo foi avaliar clinicamente a condição bucal e investigar os hábitos de praticantes de atividades físicas amadoras de maneira a auxiliar no maior reconhecimento do cirurgião-dentista dentro do ambiente esportivo visando à prevenção de possíveis lesões.

\section{Resultados e Discussão}

O estudo foi aprovado pelo Comitê de Ética em Pesquisa da Faculdade de Odontologia de Piracicaba UNICAMP, pelo CAAE: 00931118.8.0000.541.

A amostra selecionada foi de adolescentes de 15-18 anos que praticam atividade física regularmente em escolinhas de futebol da cidade de Piracicaba - SP; que responderam um questionário sobre os hábitos durante a prática esportiva e conhecimentos em relação a atuação do dentista no ambiente esportivo, além de serem submetidos a exame clínico intraoral para verificar a condição bucal.

16 adolescentes foram avaliados e os seguintes valores foram encontrados:

Em relação ao uso de protetor bucal durante a prática de atividades físicas, $81 \%$ dos entrevistados relataram achar importante o uso, porém apenas 19\% realmente o fazem.

Outro ponto relevante foi a constatação de que a maioria dos adolescentes não estão familiarizados com a presença no dentista na equipe multidisciplinar envolvida com os esportistas e não realizam tratamento odontológico visando uma melhora nos resultados físicos.

* Em relação aos medicamentos receitados em Odontologia, nenhum dos entrevistados soube responder que eles podem sim ser considerados doping (75\% não sabem, e $25 \%$ responderam não).

Poucos adolescentes participam de programas de saúde bucal como atletas (81\%) do total de participantes, apenas $19 \%$ dos atletas fazem acompanhamento com cirurgião-dentista.

* Quanto aos achados clínicos, os aspectos mais relevantes encontrados foram as alterações da normalidade na articulação temporomandibular e a quantidade de participantes que são considerados respiradores bucais (presente em $50 \%$ dos atletas avaliados). Tal alteração é de extrema importância, pois, a respiração bucal demanda maior esforço físico por parte do atleta, fazendo com que ele fique cansado com maior rapidez.

A saúde bucal dos adolescentes avaliados, em geral, foi considerada boa, tanto em relação a presença de lesões cariosas quanto a condição periodontal. Nenhum dos atletas apresentou condição periodontal severa, 50\% apresentou condição regular e 50\% apresentou condição periodontal boa.

* Em relação a presença de cárie, $75 \%$ dos atletas não apresentou nenhuma lesão ativa .

\section{Conclusões}

O estudo permiti concluir que a atuação do cirurgião-dentista no ambiente esportivo ainda é pouco conhecida. Além disso, entre os atletas amadores, poucos relatam fazer acompanhamento odontológico, o que demonstra desconhecimento do impacto da saúde bucal em relação a saúde sistêmica.

\section{Agradecimentos}

À UNICAMP, PRP, Pesquisa financiada pelo SAE/Unicamp, Faculdade de Odontologia de Piracicaba. 